\title{
Syntone Chemistry \\ Theoretical study on the formation of glycine, alannine and serine
}

\begin{abstract}
GHEORGHE SURPATEANU*, ILEANA DENISA NISTOR², ANA-MARIA GEORGESCU², NECULAI CATALIN LUNGU³
${ }^{1}$ Academy of Romanian Scientists (AOSR), 54 Splaiul Independetei, 050094, Bucharest, Romania

${ }^{2}$ Vasile Alecsandri University of Bacãu, Department of Chemical and Food Engineering, 157 Calea Marasesti, 600115, Bacau, Romania

${ }^{3}$ Al.I. Cuza University of lasi, Faculty of Chemistry, Department of Organic Chemistry and Biochemistry, 11 Carol I Blvd., 700506, Iasi, Romania

Three synthons: methylene, nitrene and carbon monoxide form aziridinone in the presence of molecular nitrogen at low temperatures. This one, in contact with the same three synthons could form the precursors of the first proteinogenic amino acids. This paper is a theoretical, thermodynamically and reactivity study concerning the formation of the three previously named amino acids at low temperature conditions. The key intermediates are identified in the formation of the three amino acids: aziridinone, aziridinonil and methyl-aziridinonil radicals. The quantitative results, enthalpies of formation, reaction enthalpies and free energies were taken from quantum mechanical calculations acquired by density functional method (DFT): B88-LYP.
\end{abstract}

Keywords: methylene, nitrene, carbon monoxide, aziridinone, methylaziridinone

In previous papers $[1,2]$ we have shown that three syntons: methylene, nitrene and carbon monoxide at low temperature in molecular nitrogen could form aziridinone, a key compound in the formation of the first proteinogenic amino acids and of the first polypeptides. Specifically, from aziridinone and the three syntons would first obtain the precursors of all proteinogenic amino acids. In contact with the primary components of the atmosphere these would form the proteinogenic amino acids.

The chemical transformations that start with combining of the three syntons previously named and that end with the formation of proteinogenic amino acids precursors should produce only through cascade pattern [3-6] seemingly without transition states, reactions that involve a continuous decreasing of reactions systems energies, which are involved in the transition from initial states to final states.

The same precursors, by copolymerization followed by reactions with atmospheric primary components would form the first proteinogenic polypeptides.

In this paper we present the thermodynamic data and theoretical study of reactions by which can be obtained three nonessential proteinogenic amino acids [7]: glycine, alanine and serine.

\section{Experimental part \\ General procedure}

Molecular systems structures involved in the obtaining of the three proteinogenic amino acids: glycine, alanine and serine were generated and optimized by successive molecular mechanics calculations (MM3) and quantum mechanics (AM1) and DGauss B88-LYP. In the analysis developed in this study were considered only thermodynamic quantities resulting from functional density calculations B88-LYP with the basic setDZVP. To determine the reaction pathways in each situation, the calculations were initiated by starting from a hypothetical state of transition. Thereafter, the reaction pathways were analyzed tow ard the end-products and the starting products. A high degree of accuracy has been used for all calculations. We have been used the Cache Work System Library, version 7.5.0.85 [8].

\section{Results and discussions}

According to a general Scheme 1, starting from the three syntons $S$, in a first stage, aziridinone could be obtained, in the presence of molecular nitrogen, at low temperatures. This one, in the presence of the same syntons, would form

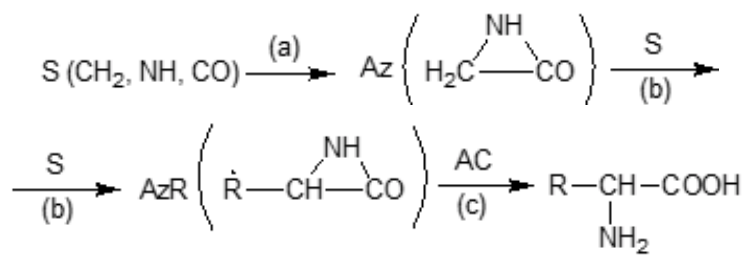

Scheme 1. Formation of proteinogenic amino acids

the precursors, radically structures, aziridinone $A z R$ derivatives, also into molecular nitrogen, at low temperatures.

The mixture of synthons precursors and molecular nitrogen, in contact with the atmosphere primary components, $\mathrm{AC}\left(\mathrm{H}_{2} \mathrm{O}, \mathrm{CO}_{2}, \mathrm{NH}_{3}, \mathrm{CH}_{4}\right.$ and $\left.\mathrm{SH}_{2}\right)$ are forming the first proteinogenic amino acids. This time, the thermodynamic conditions are more drastic, the involved reactions activation would occur more easily.

\section{Thermodynamics}

Specifically, in this theoretical study, we took into account all potentially intermediates involved in the formation of three nonessential proteinogenic amino acids: glycine $(5 ; 1)$, alanine $(8 ; 0.62)$ and serine $(9 ; 0.55)$. In brackets are indicated in order, the two indices: the complex structural factor and the participation coefficient, previously defined in paper [1]. These indices allow the assessing of possibilities for formation according to this syntonic model and for participating to polypeptides bonding formation of each proteinogenic amino acid. We repeat, it comes to appearance of the first proteinogenic amino acids and first polypeptides. 
In this paper we have been studied glycine, alanine and serine, structurally being the simplest amino acids and having a considerable share of participation in the formation of peptide bonds.

Enthalpies of formation of the involved compounds in the building of previously announced amino acids are presented in table 1.

Returning to scheme 1 , it is worth to note that in the transition from syntons to amino acids, we have three reactions denoted by $a, b$ and $c$. Specifically, it is about the formation of aziridinone, precursors and amino acids. Only the reactions of $a$ and $b$ categories must occur after photochemical reactions model, i.e. by reaction pathways in which the involved systems energies continuously decrease in passina from reactants to final products.
In table 2, according to the scheme 1 , are presented the appropriate reaction enthalpies for the formation of aziridinone, glycine, alanine and serine. In the last column, 5 , is insisted on the formation of $\mathrm{C}$-aziridinonil radical, an essential element for the formation of exocyclic C-methylaziridinonil radical. Previously [1], we have announced our results on the interaction between methylene and aziridinone. In the case of the interaction between triplet methylene and aziridinone it requires activation. It was found a transition state, superior to initial state as energy. It remains to assume that only the interaction between singlet methylene, $\mathrm{CH}_{2(5)}$ and aziridinone could generate the aziridinonil radicall. Methylene can polymerize easily. So we can take it into account by its polymethylene radicals in formation of aziridinonil radical. Why not their excited

\begin{tabular}{|c|c|c|c|}
\hline No & Product & Multiplicity & Enthalpy of formation \\
\hline 1 & $\mathrm{CH}_{2}$ & $\begin{array}{l}1 \\
3\end{array}$ & $\begin{array}{l}-39.11805 \\
-39.13453\end{array}$ \\
\hline 2 & $\mathrm{NH}$ & $\begin{array}{l}1 \\
3\end{array}$ & $\begin{array}{l}-55.13645 \\
-55.21622\end{array}$ \\
\hline 3 & $\mathrm{CO}$ & $\begin{array}{l}1 \\
3\end{array}$ & $\begin{array}{l}-113.31799 \\
-113.11143\end{array}$ \\
\hline 4 & $\mathrm{HO} \cdot$ & 2 & -75.73606 \\
\hline 5 & $\mathrm{CH}_{3}-$ & 2 & -39.81778 \\
\hline 6 & $\mathrm{CH}_{3}-\mathrm{CH}_{2}$. & 2 & -79.11817 \\
\hline 7 & $\stackrel{\mathrm{C}}{\mathrm{C}} \mathrm{H}_{2}-$ & $\begin{array}{l}1 \\
3\end{array}$ & $\begin{array}{l}-78.55754 \\
-78.42249\end{array}$ \\
\hline 8 & $\mathrm{CH}_{3}-\mathrm{CH}_{2}-\stackrel{+}{\mathrm{C}} \mathrm{H}_{2}$ & 2 & -118.41238 \\
\hline 9 & $\dot{\mathrm{C}} \mathrm{H}_{2}-\mathrm{CH}_{2}$ & $\begin{array}{l}1 \\
3 \\
\end{array}$ & $\begin{array}{l}-117.73661 \\
-117.84124 \\
\end{array}$ \\
\hline 10 & & 2 & -207.26279 \\
\hline 11 & & 2 & -246.55279 \\
\hline 12 & $\mathrm{H}_{2} \mathrm{O}$ & 1 & -76.42235 \\
\hline 13 & $\mathrm{CH}_{2}=\mathrm{NH}$ & 1 & -94.61364 \\
\hline 14 & $\mathrm{H}_{2} \mathrm{C}=\mathrm{C}=\mathrm{O}$ & 1 & -152.59353 \\
\hline 15 & $\mathrm{HN}=\mathrm{C}=\mathrm{O}$ & 1 & -168.68795 \\
\hline 16 & & 1 & -207.91957 \\
\hline 17 & $\mathrm{CH}_{3}-\mathrm{CH}-\mathrm{Co}$ & 1 & -247.22045 \\
\hline 18 & 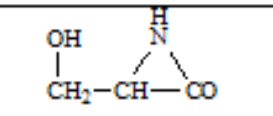 & 1 & -322.43838 \\
\hline 19 & $\mathrm{NH}_{2}$ & 1 & -284.41766 \\
\hline 20 & $\begin{array}{c}\mathrm{H}_{3} \mathrm{C}-\mathrm{CH}-\mathrm{COOH} \\
1 \\
\mathrm{NH}_{2}\end{array}$ & 1 & -323.71517 \\
\hline 21 & $\begin{array}{c}\mathrm{H}_{2} \mathrm{C}-\mathrm{CH}-\mathrm{COOH} \\
\mathrm{O}_{\mathrm{OH}} \mathrm{NH}_{2}\end{array}$ & 1 & -398.93455 \\
\hline
\end{tabular}

Table 1

ENTHALPIES OF FORMATION OF GLYCINE, ALANINE AND SERINE 
Table 2

REACTION ENTHALPIES. FORMATION OF AZIRIDINONE, GLYCINE, ALANINE AND SERINE

\begin{tabular}{|c|c|c|c|c|}
\hline No & Compound & & Reactions & $\begin{array}{l}\text { Reaction } \\
\text { enthalpies } \\
\Delta H_{\text {r (a.u.) }}\end{array}$ \\
\hline \multirow{5}{*}{1} & \multirow{5}{*}{ Aziridinone } & 1.1 & $\mathrm{CH}_{2}(\mathrm{~T})+\mathrm{NH}(\mathrm{T}) \longrightarrow \mathrm{CH}_{2}=\mathrm{NH}$ & -164.95 \\
\hline & & 1.2 & $\mathrm{CH}_{2}(\mathrm{~T})+\mathrm{CO}(\mathrm{S}) \longrightarrow \mathrm{H}_{2} \mathrm{C}=\mathrm{C}=\mathrm{O}$ & -88.45 \\
\hline & & 1.3 & $\mathrm{NH}(\mathrm{T})+\mathrm{CO}(\mathrm{S}) \longrightarrow \mathrm{HN}=\mathrm{C}=\mathrm{O}$ & -96.48 \\
\hline & & 1.4 & $\mathrm{CH}_{2}=\mathrm{NH}+\mathrm{CO}(\mathrm{S}) \longrightarrow \mathrm{H}_{2} \mathrm{C}^{\prime} \longrightarrow \mathrm{CO}$ & +7.66 \\
\hline & & 1.5 & $\mathrm{H}_{2} \mathrm{C}=\mathrm{C}=\mathrm{O}+\mathrm{NH}(\mathrm{T}) \longrightarrow \mathrm{H}_{2} \mathrm{C}$ & -68.61 \\
\hline 2 & Glycine & 2 & $-\mathrm{NH}_{2}$ & -47.84 \\
\hline \multirow{3}{*}{3} & \multirow{3}{*}{ Alanine } & 3.1 & H & -103.05 \\
\hline & & 3.2 & $+\mathrm{H} \cdot \longrightarrow \mathrm{Cl}$ & $-43.925^{*}$ \\
\hline & & 3.3 & $+\mathrm{HOH} \longrightarrow \underset{\mathrm{NH}_{2}}{\mathrm{I}}$ & -46.66 \\
\hline \multirow[b]{2}{*}{4} & \multirow[b]{2}{*}{ Serine } & 4.1 & $\rightarrow \mathrm{CH}_{2}-\mathrm{CH}$ & -93.83 \\
\hline & & 4.2 & 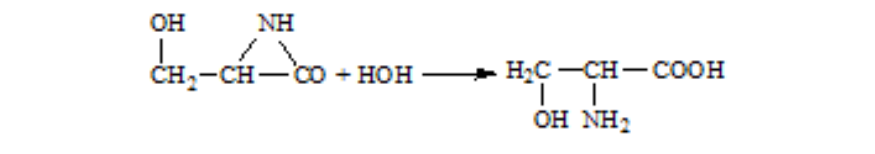 & -6.89 \\
\hline \multirow{5}{*}{5} & \multirow{5}{*}{$\begin{array}{l}\text { Aziridinonil } \\
\text { radical }\end{array}$} & 5.1 & $\mathrm{CH}_{2}(\mathrm{~T})+\mathrm{CH}_{2}-\mathrm{NH}$ & +16.60 \\
\hline & & 5.2 & $\mathrm{CH}_{3} \cdot+\mathrm{CH}_{2}-\mathrm{CO} \longrightarrow \mathrm{CH}_{4}+\mathrm{CH}-\mathrm{CO}$ & -10.66 \\
\hline & & 5.3 & $\mathrm{CH}_{2}(\mathrm{~T})+\mathrm{CH}_{2}(\mathrm{~T}) \longrightarrow \stackrel{+}{\mathrm{C}} \mathrm{H}_{2}-\dot{\mathrm{C}}_{2}$ & -96.25 \\
\hline & & 5.4 & $\mathrm{CH}_{2}+\dot{\mathrm{C}} \mathrm{H}_{2}-\stackrel{+}{\mathrm{C}} \mathrm{H}_{2} \longrightarrow \dot{\mathrm{C}}_{2}-\mathrm{CH}_{2}-\dot{\mathrm{C}} \mathrm{H}_{2}$ & -118.36 \\
\hline & & 5.5 & $\mathrm{CH}_{2}-\mathrm{CO}+\dot{\mathrm{C}}_{2}-\mathrm{CH}_{2}-\dot{\mathrm{C}} \mathrm{H}_{2} \longrightarrow \dot{\mathrm{C}} \mathrm{H}-\mathrm{CO}+\mathrm{CH}_{3}-\mathrm{CH}_{2}-\dot{\mathrm{C}} \mathrm{H}_{2}$ & -47.39 \\
\hline
\end{tabular}

superior states could be involved? The presence of light in these reactions is practically mandatory.

A simple calculation of reaction enthalpy can eliminate those transformations that do not fit in the continuous decreasing model of reaction system energy. Of course these would be endothermic reactions.

As we are interested in choosing those transformations which would lead to the formation of the three proteinogenic amino acids, in table 2 is normal to find almost all reactions as exothermic ones.

Aldimine, ketene, isocyanate acid, glycine are detected interstellar compounds [9-18]. Very interesting is that aziridinone was detected by mass spectrometry as a breakdown product of some oligopeptides [19]. Why nota formation of proteinogenic acids and of polypeptides from aziridinone?

A careful analysis of transformations presented in table 2 leads us to several observations. Among the primary components of the atmosphere, only water participates to the formation of glycine, alanine and serine. Among the reactions involved in the formation of aziridinone, the one between aldimine and carbon monoxide is endothermic and therefore it is unlikely at very low temperatures. The reactions between ketene with nitrene and between isocyanic acid with methylene remain in competition. In the next section, the favored reaction between these two ones will be chosen. Most likely, the glycine is obtained by aziridinone hydrolysis. 


\begin{tabular}{|c|c|c|c|c|}
\hline No. & Id & $\Delta H_{i}$ & $\Delta H_{j}$ & $\Delta G 200 / 300 \mathrm{~K}$ (a.u.) \\
\hline 1 & 1.2 & -152.45252 & -152.59353 & $\begin{array}{l}-152.57775 \\
-152.58643\end{array}$ \\
\hline 2 & 1.3 & -168.32765 & -168.68795 & -207.88738 \\
\hline 3 & 1.5 & -247.03762 & -247.08057 & -207.89731 \\
\hline 4 & 1.6 & -207.82248 & -207.91937 & -207.88734 \\
\hline 5 & 5.2 & -247.73735 & -247.75438 & -207.89727 \\
\hline 6 & 3.1 & -246.39732 & -246.55279 & -246.54932 \\
\hline 7 & 3.2 & -247.15011 & -247.22045 & -247.17246 \\
\hline 8 & 4.1 & -322.28885 & -322.43838 & -322.39203 \\
\hline
\end{tabular}

Table 3

ENTHALPIES AND FREE ENERGIES IN THE FORMATION OF AZIRIDINONE, GLYCINE, ALANINE AND SERINE
The appearance of methyl aziridinonil radical is essential in the obtaining of alanine and serine. This one forms alanine with the mobile hydrogen from water or from elsewhere. Serine is obtained from methyl aziridinonil radical with the hydroxide from water too.

It should be noted that hydrogen cannotbe evaluated as a distinct chemical entity as in reaction 3.2 of table 2. It has been started from a transition compound between hydrogen and methylaziridinonil radical as initial state. In other words, the reaction enthalpy value for this case has to be taken with sufficient reserves.

\section{Reaction pathways}

We remind that for the formation of all amino acids intermediaries and precursors we have to choose only those reaction pathways in which the transition from the starting compounds to the reaction products to have a decreasing of reactional energy systems values.

That's why were chosen the reactions which respond to this requirement and of course, which lead to obtaining of the three proteinogenic amino acids: glycine, alanine and serine. These reactions are presented in Table 3 . In the second column of table 3 , are specified the reactions from table 2. A careful analysis of the data from table 3 allows us to make some remarks.

Most likely, aziridinone is obtained from ketene and nitrene, according to reaction 1.5 (tables 2 and 3), taking in account the free energies values for the reactions 1.5 and 1.6. This means that aldimine and isocyanic acid are excluded. Perhaps it is time to remember that the three syntons can form a large number of compounds, which can in their turn, further diversify the composition of mixtures. In our study we refer only to those compounds and those reactions that lead to the three analyzed amino acids.

Concerning the aziridinonil radical formation, most likely it would arise from the action of methylene singlet on the aziridinone. That is not the only, others reactions are possible (5.2 and 5.5).

The formation of $\mathrm{C}$-methylaziridinonil radical formation from methylene and aziridinonil radical is clearly possible (reaction 3.1, table 3). This latest radical, in contact with water offers easily serine (reaction 4.1).

As we told previously, the hydrogen atom is unable as a free chemical entity. Formally, we used the hydroxyl radical as partner of reaction in formation of serine.

In figure 1 are shown sequentially the general shape of the reaction pathw ays curves and a concrete example, for reaction 3.1 .
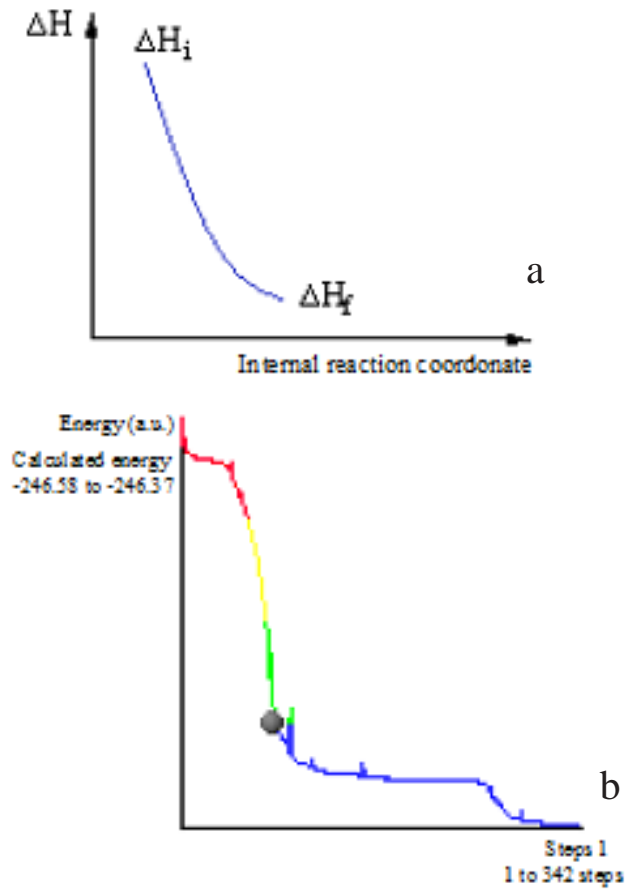

Fig. 1. General allure of all reaction pathways from table $3(a)$; Formation of methyl-aziridinonil radical, reaction 3.1 (b)

\section{Conclusions}

Several conclusions can be highlighted:

- Formation of the three proteinogenic amino acids: glycine, alanine and serine can occur through aziridinone.

-Aziridinone, the most likely can be obtained starting from the three syntons: methylene, nitrene and carbon monoxide, first by forming of ketene, which then will react with nitrene.

- Glycine is obtained by hydrolysis of aziridinone or aziridinonil radical.

-Alanine and serine have a common precursor, carbon exocyclic radical of methylaziridinone.

-Concerning the precursor hydrolysis, we believe that the precursor radicals would react with water more quickly than lactamic derivatives.

-We could suggest the performing of some experiments starting from the three syntons. Methylene can be generated from diazomethane. Nitrene may be obtained from sodium azide. Carbon monoxide is easily accessible.

-Syntons can be captured in liquid nitrogen. Nitrogen stabilizes these syntons and can be considered a quasiinert reaction media.

-Operation and experimental assembly on obtaining of amino acids and polypeptides have been announced in a previous paper [1]. 
This research did not receive any specific grant from funding agencies in the public, commercial, or not-forprofit sectors.

\section{References}

1. SURPATEANU, G., Int. J. Astrobiology, 17, no. 4, 2017, p. 361.

2. SURPATEANU, G., LUNGU, N.C., Rev. Chim., (Bucharest), 62, no.

11, 2011, p. 1486.

3. BERNARDI, F., OLIVUCCI, M., ROBB, M. A., Chem. Soc. Rev., 25, 1996, p. 321.

4. BALTRUSAITIS, J., PATTERSON, E., HATCH, C., J. Phys. Chem. A, 116, 2012, p. 9331.

5. SIMS, I. R., SMITH, I. W. M., Ann. Rev. Phys. Chem., 46, 1995, p. 109.

6. JUNG, SE-H.,J ANG, SU-C., KIM, JIN-W., KIM, JANG-W., CHOI, JONGH., J. Phys. Chem. A, 119, 2015, p. 11761.

7. PERES, H., OLIVA-TELES, A., Aquaculture, 256, 2006, p. 395.

8. Cache Worksystem Library version 7.5.0.85 (2006). Fujitsu, Poland.

9. MILLER, S. L., Science, 117, 1953, 528.
10. SCHLESINGER, G., MILLER, S. L., J. Mol. Evol., 19, 1983, p. 376.

11. ELSILA, J. E., GLAVIN, D. P., DWORKIN, J. P., Meteorit. Planet. Sci., 44, 2009, p. 1323.

12. BLAGOJ EVIC, V., PETRIE, S., BOHME, D. K., Mon. Not. R. Astron. Soc., 339, 2003, L7.

13. SORRELL, W. H.,Astrophys. J., 555, 2001, L129.

14. BRACK, A., Chem. Biodivers., 4, 2007, p. 665.

15. WINCEL, H., FOKKEN, R. H., NIBBERING, N. M. M., Rapid Commun. Mass Spectrom., 14, 2000, p. 135.

16. EHRENFREUND, P., BERNSTEIN, M. P., DWORKIN, J. P., SANFORD, S. A., ALLAMANDOLA, L. J., Astrophys. J., 550, 2001, L95.

17. THADDEUS, P., Phil. Trans. R. Soc. B., 361, 2006, p. 1681.

18. TAKANO, Y., TAKAHASHI, J., KANEKO, T., MARUMO, K., KOBAYASHI, K., Earth Planet. Sc. Lett., 254, 2007, p. 106.

19. SHUSTOV,G. V., KACHANOV, A. V., CHERVIN, I. I., KOSTYANOVSKY, R. G., RAUK, A., Can. J. Chem., 72, 1994, p. 279.

$\overline{\text { Manuscript received: } 19.11 .2018}$ 